\title{
The Emergence of the Structure of the Molecule and the Art of Its Synthesis
}

\author{
K. C. Nicolaou*
}

At the core of the science of chemistry lie the structure of the molecule, the art of its synthesis, and the design of function within it. These attributes elevate chemistry to an essential, indispensable, and powerful discipline whose impact on the life and materials sciences is paramount, undisputed, and expanding. Indeed, today the combination of structure, synthesis, and function is driving many scientific frontiers forward, including drug discovery and development, biology and biotechnology, materials science and nanotechnology, and molecular devices of all kinds. What connects structure and function is synthesis, whose flagship is total synthesis, the art of constructing the molecules of nature and their derivatives. The power of chemical synthesis at any given time is reflected and symbolized by the state of the art of total synthesis, and as such the condition and sophistication of the latter needs to be continuously nourished and advanced. In this review the understanding of the structure of the molecule, the emergence of organic synthesis, and the art of total synthesis are traced from the nineteenth century to the present day.

\section{Introduction}

The celebration of Angewandte Chemie's $125^{\text {th }}$ anniversary in 2013 gives us the opportunity to reflect on both the past and the future of the central, and yet universal and ubiquitous, science of chemistry. Indeed, chemistry is the scientific bridge that connects the macrocosm with the microcosm, our perceived visible world with the invisible world of atoms and molecules. As such chemistry helps us understand nature and provides the foundation upon which we stand as we attempt to exploit it while preserving and sustaining it for generations to come.

Today, the state of the science of chemistry is quite sharp. As it strives to advance itself to a higher level of sophistication, it is being called upon by many disciplines to enable advances and inventions in an impressive array of fields ranging from health care, nutrition, energy, high tech materials, and tools to monitor, unravel, and apply complex biology. Why is chemistry so fundamental to so many

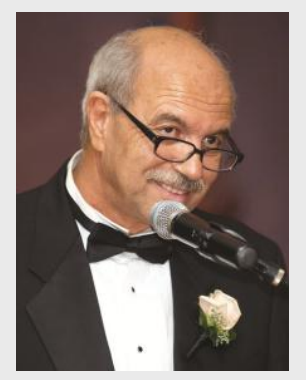

K. C. Nicolaou, born in Cyprus and educated in UK and USA, is Chairman of the Department of Chemistry at The Scripps Research Institute where he holds the Darlene Shiley Chair in Chemistry and Aline W. \& L. S. Skaggs Professorship in Chemical Biology, and is Distinguished Professor of Chemistry at the University of California, San Diego. The impact of his work in chemistry, biology and medicine

flows from his contributions to chemical synthesis as described in over 700 publications. His dedication to chemical education is reflected in his Classics in Total Synthesis book series and Molecules That Changed the World, and his training of hundreds of graduate students and postdoctoral fellows. He is a Member of the National Academy of Sciences (USA), the German Academy of Sciences Leopoldina, and the American Philosophical Society, and Corresponding Member of the Academy of Athens. other sciences, technologies, and engineering, and how did it come to be so advanced and enabling? The power of chemistry is primarily derived from its ability to understand molecular structure, synthesize it, and build function within it through molecular design and synthesis.

Thus, the emergence of the concept of the atom initially in the fifth century $\mathrm{BC}$, and subsequently during the renaissance of the eighteenth and nineteenth centuries, and that of the molecule in the nineteenth century, together with the advent of organic synthesis in the latter century, constituted a monumental advance in science. To appreciate the impact of these developments we only have to trace the origins of the modern frontiers in chemistry, biology, biotechnology, medicine, materials science, nanotechnology and so many other disciplines that rely on the molecule, its construction, and its use. To be sure, chemistry benefited from other scientific developments and disciplines, just as it enabled other sciences and industries. Thus, quantum mechanics, analytical methods and instrumentation, and biological techniques, among others, all have benefited structural elucidation and chemical synthesis, while physics, biology and medicine provided opportunities and challenged chemistry to deliver tools and function, thereby expanding the scope and reach of chemistry beyond boundaries previously imagined.

One of the most vital and valued subdisciplines of chemistry is the science of organic synthesis, without which much of science and industry would have remained paralyzed and sterile. This is the discipline that provides the myriad of molecules from which emerge our most precious new material goods and gadgets, whether they are instruments to cure disease and promote wellness or tools that help us build machines, communicate, travel and entertain ourselves, not to mention advance education and science, and achieve sustainability. The flagship of organic synthesis is the art of total synthesis, the branch of synthesis that deals with the construction of nature's molecules of life.

While it is widely accepted that the roots of literature and many of the modern arts can be traced back to Ancient Greece, it is less 
well known that the same can be said for much of modern science. ${ }^{[1,2]}$ This statement rings particularly true for the original concept of the atom as articulated by Demokritos (460-370 BC) and his lesser known teacher, Leukippos (500-430 BC), in the fifth century BC. The fundamental nature of Demokritos' atomic theory is appropriately encapsulated in the following description by George Sarton in his book Ancient Science Through the Golden Age of Greece: ${ }^{[1]}$

"The world is made of two parts, the full (plères, stereon) and the empty, the vacuum (cenon, manon). The fullness is divided into small particles called atoms (atomon, that cannot be cut, indivisible). The atoms are infinite in number, eternal, absolutely simple; they are all alike in quality but differ in shape, order, and position. Every substance, every single object, is made up of those atoms, the possible combinations of which are infinite in an infinity of ways. The objects exist as long as the atoms constituting them remain together; they cease to exist when their atoms move away from one another. The endless changes of reality are due to the continual aggregation and disaggregation of atoms."

While philosophy and imagination may be considered as the precursor to modern atomic theory, alchemy may be viewed as the ancestral discipline of modern practical chemistry. This should not diminish the importance of metallurgy and related practices in the ancient worlds of Babylon, Egypt, Greece, China, and Rome, which were impressively advanced as evidenced from the myriad artifacts that they left.

Prevailing in the middle ages, alchemy has a mixed reputation. The alchemists were often suspect characters, whose endeavors were associated with secrecy, myth, superstition, charlatanism, and even satanism. The culture of secrecy amongst alchemists goes back to the early days of metallurgy, when the knowledge of how to extract and manipulate metals was valued to the extreme as it could bring riches, power, and dominance. However, this secrecy left alchemy open to justifiable criticism, accusations of deceit, and outright thievery. Many alchemists would fraudulently promise to deliver gold through the precious philosopher's stone, from common metals, and thus the secret of longevity to those who could afford it. Some of the practitioners were even executed after they failed to deliver on such promises made to those in power. However, amongst the alchemists were some talented individuals who made significant contributions to the development of chemistry. It is fair to say, therefore, the term alchemist encompassed a wide spectrum of characters ranging from genuine scientists to pure criminals, with philosophers and conjurers in between. The French chemist Marcellin Berthelot (1827-1907), who studied and wrote extensively about alchemy, ${ }^{[3]}$ supported the notion that this 'art' was the adolescent that grew into the modern science of chemistry.

Paracelsus (born Philippus Aureolus Theophrastus Bombastus von Hohenheim, 1493-1541), a famous Swiss alchemist and physician, became renowned for his recipes to treat various diseases and believed in the equivalence of poisons and medicines. With his famous statement, "Alle Ding' sind Gift, und nichts ohn' Gift; allein die Dosis macht, daß ein Ding kein Gift ist," ("All things are poison, and nothing is without poison; only the dose makes that a thing is not poison"), he proclaimed that the action of these substances depends only on the right dose, a principle that is now known to be correct, more or less. He insisted that, "...no doctor could afford to ignore the art of chemistry...," and he championed the use of chemicals or plant extracts to treat serious diseases. Indeed, he is credited with the popularization of opium as a treatment for many ailments, and for recreational purposes as it turned out. Paracelsus also discovered hydrogen, which he produced by the action of sulfuric acid on iron filings and named it 'burning gas'. This gas was rediscovered and better defined by Henry Cavendish (17311810), who named it "inflammable air". Hennig Brand (16301710), another famous German alchemist, discovered phosphorus by accident in 1669; phosphorus was the first element to be discovered in the modern era.

Queen Christina of Sweden (1626-1689) was said to have been impressed with alchemy. She wrote, in 1667, of the successful conversion of five hundred pounds of lead into gold by a Dutchman using a mere grain of red powder. She went on to praise chemistry as a "...beautiful science and the key which opens all treasures, giving health, glory and wisdom," and despite her regrets that chemistry had been defamed by charlatans, she declared that it remained the royal science. ${ }^{[4]}$ By the time Queen Christina was entertained by such tricks, alchemy was on the decline, although it would be another century before it would finally be confined to the history books.

Alchemy slowly gave rise to the renaissance of thought about matter and the birth of true chemistry. Being both an alchemist and a chemist, Robert Boyle (1627-1691), ${ }^{[5]}$ born in English-occupied Ireland, perhaps represents more than any other the transition of alchemy to 'modern chemistry'. Although Boyle has been often called the father of modern chemistry, his chemistry was not modern. But while the discipline's ascent is too complex and it happened gradually step by step, Boyle can justly be considered as a grandfather of modern chemistry. His main contributions were his championing of chemical and corpuscular philosophies and development of the experimental method in chemistry. The latter was promoted by the newly established Royal Society of London. Boyle's ideas were expressed in his most famous book, The Sceptical Chymist, published in 1661, one year after the Royal Society was founded. While he was described as a 'great alchemist', Boyle was also an experimentalist. His method was based on data, purity and quantification. ${ }^{[6-8]}$

Quantification and experimental evidence was brought to a new level by Antoine-Laurent de Lavoisier (1743-1794) ${ }^{[9]}$ (Figure 1) whose contributions represent a quantum advance in the emergence of modern chemistry. Lavoisier - in the minds of many the father of modern chemistry - based his theoretical assumptions on combustion. In his Traité élémentaire de chemie he described his experiments and chemical philosophy that provided the foundation onto which the new science of chemistry was to be developed in the nineteenth century. Lavoisier's central element was oxygen, as it played crucial roles in both combustion and acidity-basicity. Thus, acids were higher oxides of nonmetals, bases were lower oxides of metals. Organic acids were compounds made of hydrocarbon radicals and oxygen, salts were products of combining acids and bases. The few exceptions to the rules such as the requirement for oxygen in an acid were thought of as being due to the limitations of the experimental analytical techniques of the day. ${ }^{[6-8]}$

Lavoisier published a list of elements (including "inflammable air" which he named "hydrogen") which he defined more precisely than Boyle did before him. His cautionary warning that his listings were to be counted as elements only until they are proven otherwise by further decomposition turned into a prophecy, as some of them were proven wrong through subsequent experimentation. The provisional status of his list of elements was underscored by his words:

"Thus, as chemistry advances towards perfection, by dividing and subdividing, it is impossible to say where it is to end; and 
these things we at present suppose simple may soon be found quite otherwise. All that we dare venture to affirm of any substance is, that it must be considered as simple in the present state of our knowledge, and as far as chemical analysis has hitherto been able to show." $[8]$

Lavoisier, however, had no other way to distinguish between ultimate atoms and chemical elements. That distinction and clarification had to await several decades, much experimentation, and fierce debates.

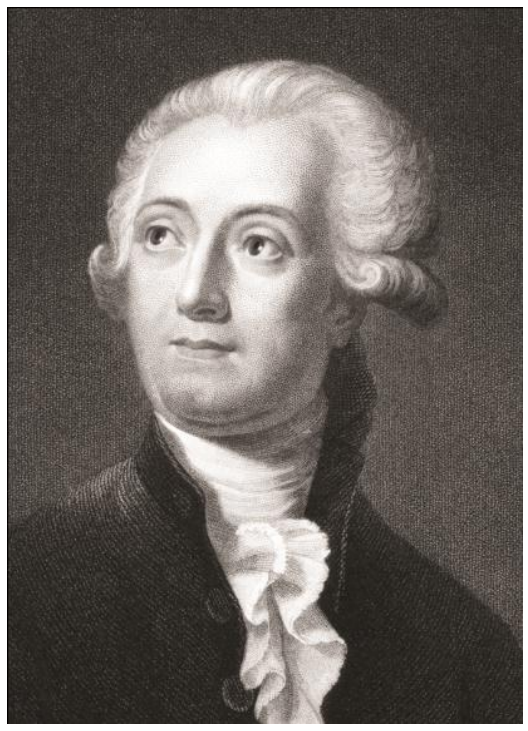

Figure 1. Antoine-Laurent de Lavoisier (1743-1794). (C) iStockphoto.com, GeorgiosArt)

Descending from alchemy as it did, eighteenth century chemistry, including Lavoisier's, was primarily inorganic in nature. It dealt with the metals and the gases and their compounds. Organic chemistry would acquire momentum and take shape in the nineteenth century and from it would be born organic synthesis and natural products chemistry. Its roots, however, can be traced to the eighteenth century and the work of the apothecaries and physicians who wielded enormous power at the time, for they were the keepers and providers of medicine to cure disease. One of them was Carl Wilhelm Scheele (1742-1786) (Figure 2), a Swedish chemistapothecary. As such, he perhaps represents the transition from the practices of these characters to organic chemistry for his contributions to the latter discipline were practical and transformative. Thus, besides credited for the discoveries of oxygen (before Priestley) and pasteurization (before Pasteur), Scheele discovered prussic, citric, oxalic, uric, gallic, malic and lactic acids and developed and employed several laboratory techniques. ${ }^{[6-8]}$

In this article, we will review the emergence of organic chemistry ${ }^{[6-8]}$ and its principles and applications with emphasis on the key developments in the nineteenth century that led to the structure theory, organic synthesis, and natural products total synthesis. ${ }^{[10-12]}$

\section{The Emergence of Chemical Atomism and the Structure of the Molecule}

In describing the rather turbulent events that led to the establishment of the atomic theory and the structure of the molecule in the nineteenth century it is appropriate to begin with John Dalton (1766-1844) (Figure 3). ${ }^{[13]}$ His contributions were enormously influential and occurred at the very dawn of this era. Dalton argued convincingly that chemical atoms were also physical atoms, introduced the chemical atomic theory, and started the chemical atomism movement in the first decade of the nineteenth century. Central to his ideas was the axiom that atoms were the least part of the chemical elements. In addition to the atomic theory, Dalton discovered and championed a number of numerical laws and guidelines defining the rules by which chemical combinations were governed. Among his rules were the law of partial pressures and the law of multiple proportions. His atomic theory led to atomic weights that were not necessarily the same as equivalent weights. The two would be recognized later as being related through valency (the number of other atoms a given atom can combine with) by the equation: atomic weight $=$ valency $\times$ equivalent weight. $\mathrm{He}$ introduced symbols for each element and groups of such symbols to represent molecules in which the number of atoms of each element could be defined.

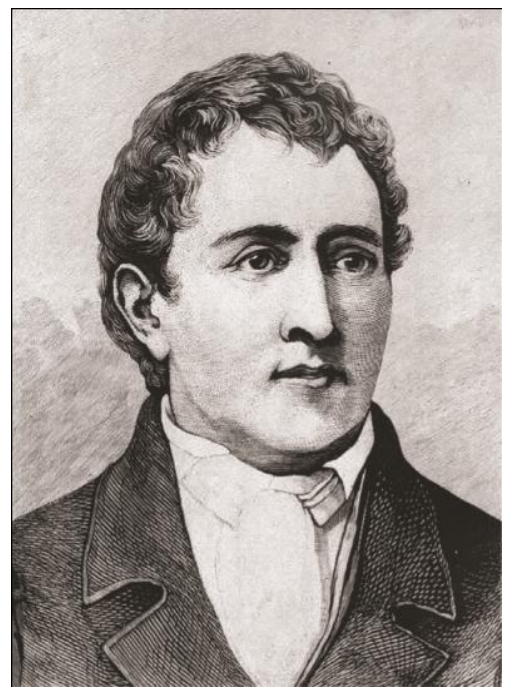

Figure 2. Carl Wilhelm Scheele (1742-1786). (Courtesy of the Edgar Fahs Smith Collection, University of Pennsylvania)

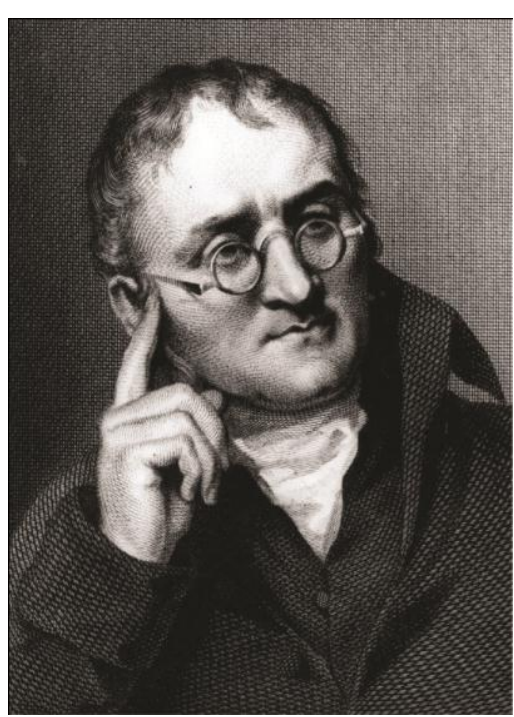

Figure 3. John Dalton (1766-1844). (Courtesy of the Edgar Fahs Smith Collection, University of Pennsylvania) 
According to Alan Rocke, ${ }^{[6]}$ one of the earliest to hear from Dalton on his ideas on atoms was the Scottish chemist Thomas Thompson who later wrote in vivid terms:

"In the year 1804, on the $26^{\text {th }}$ of August, I spent a day or two at Manchester, and was much with Mr. Dalton. At that time he explained to me his notions respecting the composition of bodies. I wrote down at the time the opinions which he offered, and the following account is taken literally from my journal of that date:

The ultimate particles of all simple bodies are atoms incapable of further division. These atoms (at least viewed along with their atmospheres of heat) are all spheres, and are each of them possessed of particular weights, which maybe be denoted by numbers. For the greater clearness he represented the atoms of the simple bodies by symbols....

It was this happy idea of representing the atoms and constitution of bodies by symbols that gave Mr. Dalton's opinions so much clearness. I was delighted with the new light which immediately struck my mind, and saw at a glance the immense importance of such a theory, when fully developed.'

With his ideas Dalton went beyond Lavoisier in defining the chemical atom as a physical atom. The latter thought of atoms as metaphysical and that we could not obtain evidence of them or their properties through experimentation. Lavoisier's chemical elements were the ultimate products of analysis, while Dalton believed that besides being the least part, the ultimate atoms of the different chemical elements were different from one another in their weights. ${ }^{[6-8]}$

A contemporary, if not a rival, to Dalton was his fellow countryman Humphry Davy (1778-1829) (Figure 4), who introduced the voltaic pile and electrolysis to chemistry through which he discovered the alkali metals sodium and potassium by splitting soda and potash, respectively, as well as the alkali earth metals barium, strontium, calcium and magnesium, and chlorine. $\mathrm{He}$ also identified iodine and inferred the existence of fluorine. Davy was the preeminent British chemist of his time and served as President of the Royal Society of London. His lectures were legendary and made chemistry in London appealing and fashionable, a tradition that was continued and broadened by his successor,

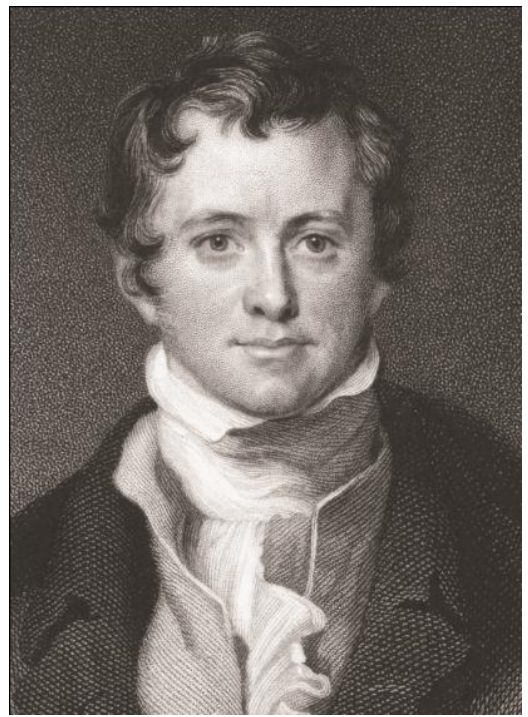

Figure 4. Humphry Davy (1778-1829). (@ iStockphoto.com, GeorgiosArt)
Michael Faraday (1791-1867), who established the famous Christmas Lectures for children and popularized science. Following Lavoisier's assertion that sharper methods of analysis could lead to the discovery of new elements, he employed his voltaic battery apparatus and succeeded in resolving numerous compounds into their constituents. Unlike Dalton, however, he favored equivalents more than atoms and was skeptical of the atomic theory. He thought of the existence of only a limited number of elements, perhaps even one, which was in line with his Newtonian theory of the simplicity of nature. As President of the Royal Society, Davy made it clear in bestowing the Royal Medal on Dalton that the award was for the law of combining proportions rather than the atomic hypothesis, and he referred to him as the Kepler of chemistry (rather than Newton), signaling his skepticism about Dalton's atomic theory. ${ }^{[6-8]}$

Another emerging figure in chemistry at the dawn of the nineteenth century was the Swedish chemist Jöns Jakob Berzelius (1779-1848) (Figure 5). He had powerful laboratory skills and techniques, and the ability to assimilate, classify, and promote ideas and concepts throughout Europe, becoming one of the most influential figures of chemistry in the first decades of that century. He borrowed from both Lavoisier and Dalton and benefited from his interactions with Davy. He applied effectively atomic and electrochemical principles, thereby providing a unified theory of chemistry at the heart of which were his ideas of electrochemical dualism. ${ }^{[6-8]}$

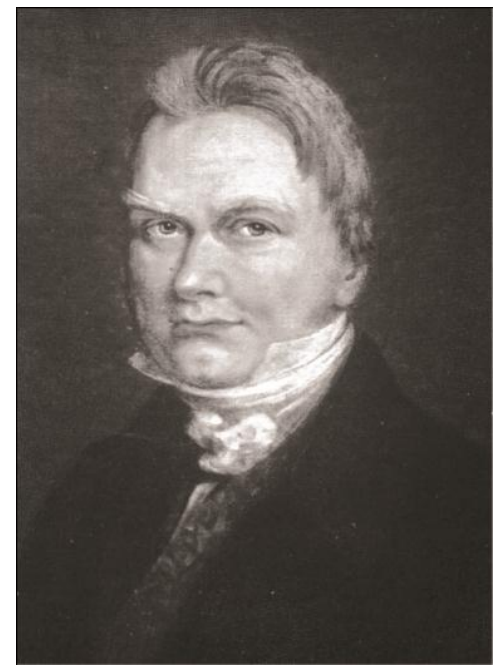

Figure 5. Jöns Jakob Berzelius (1779-1848). (Ladsgroup, Wikimedia Commons, Public Domain)

Just like Dalton, Berzelius based his chemical philosophy on Lavoiserian principles, namely gravitational stoichiometry and the constancy of basic oxygen. However, he differentiated his atomism from that of Dalton in that his was derived from experiment and moved to theory, whereas Dalton's moved from theory to experiment. As quoted by Rocke, ${ }^{[6]}$ Berzelius noted in 1814-1815:

"Mr. Dalton has chosen the method of an inventor, by setting out from a first principle, from which he endeavors to deduce the experimental results. For my own part, I have been obliged to take the road of an ordinary man, collecting together a number of experiments, from which I have endeavored to draw conclusions more and more general. I have endeavored to mount from experiment towards the first principle; while Mr. Dalton descends from that principle to experiment." 
This statement should not, however, take away from Berzelius' strong advocacy and belief in chemical theory and hypothesis. He exerted his influence through his travels, writings and, above all, his students who were planted in key positions in Europe, particularly Germany. Berzelius' most influential student, Friedrich Wöhler $(1800-1882),{ }^{[14]}$ was destined to play a crucial role in the history of organic chemistry. Wöhler was appointed Professor of Chemistry at the University of Göttingen from where he translated Berzelius' writings from Swedish to German, thereby propagating his ideas and influence throughout the German speaking community of Europe.

In the meantime, the stature of another influential figure in European chemistry was rising in France. Gay-Lussac (1778-1850) (Figure 6), together with Louis Jaques Thenard (1777-1857), introduced the first reliable methods for elemental analysis of organic compounds. This was based on heating the substance in a glass tube with potassium chlorate as an oxidant and measuring the amount of carbon dioxide formed. Gay-Lussac went on to make further important contributions to the advancement of organic chemistry as we shall see later. Most importantly, his impact on the science of chemistry would also be exerted through his students, of whom the most influential was Justus von Liebig (1803-1873). ${ }^{[15]}$

Liebig returned to Giessen in Germany from Paris at about the same time as Wöhler returned from Stockholm to Göttingen, and the two would eventually become friends and collaborators. Together and through their work on the cyanates and fulminates they discovered the phenomenon of isomerism, which contributed to the understanding of the structure of the molecule. Their collaborative work on the "benzoyl" (benzaldehyde) which they isolated from bitter almonds, led to the definition of the "benzoyl radical", a group of atoms that went through a series of reactions without change. This radical would later be redefined as the "phenyl radical" through the diligent work of Eilhard Mitscherlich (1794-1863) despite the initial objections of Liebig. ${ }^{[6-8]}$

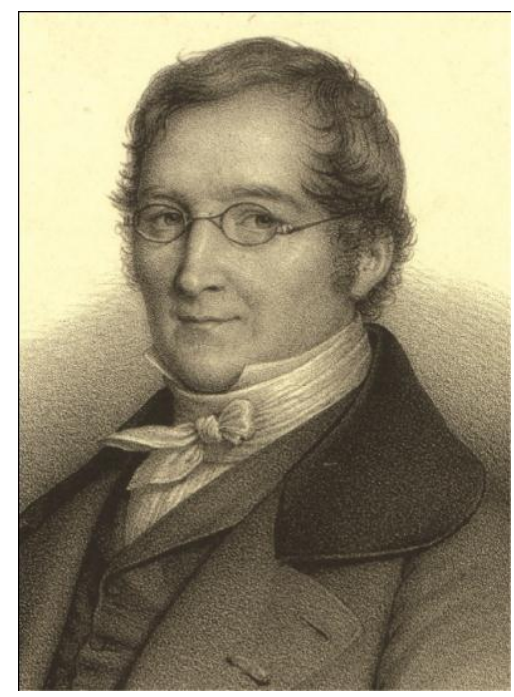

Figure 6. Joseph Gay-Lussac (1778-1850). (Daderot, Wikimedia Commons, Public Domain)

The chemistry of Lavoisier, Dalton, Berzelius and Gay-Lussac was primarily inorganic and included gases and elements. The rise of organic chemistry begun at the passing of the eighteenth to the nineteenth century and it took several decades before it would mature into an exact science. The first steps toward this quest were taken by Lavoisier and Berzelius, the former with his studies on organic acids and salts and physiological chemistry, and the latter with his reliable elemental analyses of organic substances. Berzelius was adamant that the theories and methods of inorganic chemistry could be applied to explain structure and properties in organic chemistry, thereby making progress in the latter branch of chemistry. His conservatism and beliefs in first experiment and then theory, however, led him to insist on his electrochemical dualism for too long, until overwhelming events would overtake his views. ${ }^{[6-8]}$

Jean-Baptiste André Dumas (1800-1884) was instrumental in ushering in the era of substitution in chemistry. In 1834, he published his theory of substitution using the replacement of hydrogens with chlorines in alcohol to produce chloral as his main example. ${ }^{[6,16]}$ The young Frenchman Auguste Laurent (1807-1853), a student of Dumas', would make the next step of departure from Berzelius' dualism with his 1836 doctoral thesis in which he challenged Berzelius' theory and presented his own. ${ }^{[8]}$ Through experimentation, Laurent substituted one hydrogen atom with a chlorine atom on the methyl radical of acetic acid, and observed very similar properties for the newly formed acid. Since hydrogen was electropositive and chlorine electronegative, this meant the arrangement of the atoms within the molecule matters more than the nature of the atoms in determining its properties, a notion that went against the dualism theory. Berzelius disagreed, Dumas and Laurent's ideas and observations remained dormant until further ideas and personalities came along. In 1845 Laurent and Charles Gerhardt $(1816-1856)^{[17]}$ combined their ideas and efforts to bring order to the increasingly chaotic universe of organic compounds whose numbers were rapidly increasing. They proposed two sets of classification, which are associated more with Gerhardt than Laurent, that of "homologous" as in the series of "paraffins" and "alcohols", and that of "types" as in "water type" and "amine type". Proposed in 1853 , the theory of types was based on the idea of substitution and assumed that all organic compounds belonged to three fundamental types, those derived from hydrogen $(\mathrm{H}-\mathrm{H})$, water $(\mathrm{H}-\mathrm{O}-\mathrm{H})$, and ammonia $[\mathrm{H}-\mathrm{N}-(\mathrm{H})-(\mathrm{H})]$. Since hydrogen, water, and ammonia were all inorganic, the type theory provided a bridge between organic and inorganic chemistry, a feature that added to its attractiveness. $^{[6-8]}$

To the emergence of Dumas, Gerhardt, and Laurent's theory of substitution and types contributed several other chemists, the most prominent being the Englishman Alexander Williamson (18241904), whose landmark synthesis of ether and its classification as of the "water type" in the early 1850 s proved path-pointing and influential. In addition to prompting Gerhardt to prepare, starting in 1852, a number of acid anhydrides, of which that of benzoic acid was the first, Williamson's work impacted the work of William Odling (1829-1921), C. Adolphe Wurtz (1817-1884), and August Kekulé (1829-1896), all of whom would contribute significantly to the soon to emerge theories of valence and structure. In the 1840s, Liebig proclaimed that ammonia could be viewed as "the type of all organic bases" and suggested that the ethyl-substituted ammonia could be prepared. His prediction would soon be confirmed by two of his students, Wurtz, who prepared ethylamine, and August Wilhelm von Hofmann (1818-1892), who synthesized a series of secondary and tertiary amines. Williamson's original synthesis of ether and other ether types, and his concepts of "monobasic" and "dibasic" groups were gathering momentum. According to Alan Rocke, ${ }^{[6]}$ these ideas held "the seed of the theories of valence and structure". If Williamson was the seeder of the theory of types, Gerhardt, with contributions from Laurent, was its master composer. $^{[6]}$

The radical theory was initially conceptualized by Lavoisier to explain salt formation from inorganic and organic acids, and 
subsequently expanded by Dalton's atomic theory and Berzelius' ideas on electrochemical dualism. Radicals in general were perceived as stable assemblies of atoms that were sustained as such throughout various chemical transformations. Liebig and Wöhler's collaborative work and recognition of the "benzoyl" (in reality phenyl) radical in 1832 signaled the entrance of the radical concept from the inorganic to the organic domain of chemistry. From then on the radical theory would gather momentum and become main stream as more radicals were demonstrated and added to the list. ${ }^{[6]}$

Although differing significantly in the beginning, the Gerhardt theory of types and the radical theory as ushered into organic chemistry, would eventually come together and contribute to the unification of chemistry and the downfall of the old ideas, most notably Berzelius' electrochemical dualism theory. Championed by Liebig, Wöhler, and others, the revolt against Berzelius spread throughout Europe in the late 1840s and early 1850s, but the confusion over atomic weights and equivalents continued to cloud the structure of the molecule. The clouds, however, would soon begin to thin out, and the picture of the molecule would come into focus as the structural theory took shape, beginning with a number of milestone theoretical papers that appeared in the late 1850s.

A student of Liebig's, Kekule (Figure 7) learned the German philosophies of chemistry. He then enriched his knowledge with the latest theories and ideas emerging in Paris and London. The essential elements of the emerging theories of valence and structure came together from various schools, including those of Williamson, Gerhardt, Edward Frankland (1825-1899), Odling, Wurtz, Hofmann, and Kekulé. In an attempt to prepare the ethyl radical, Frankland heated zinc with ethyl iodide and obtained diethyl zinc, the first true organometallic compound. By doing so, he not only launched organometallic chemistry as a new branch of chemistry but

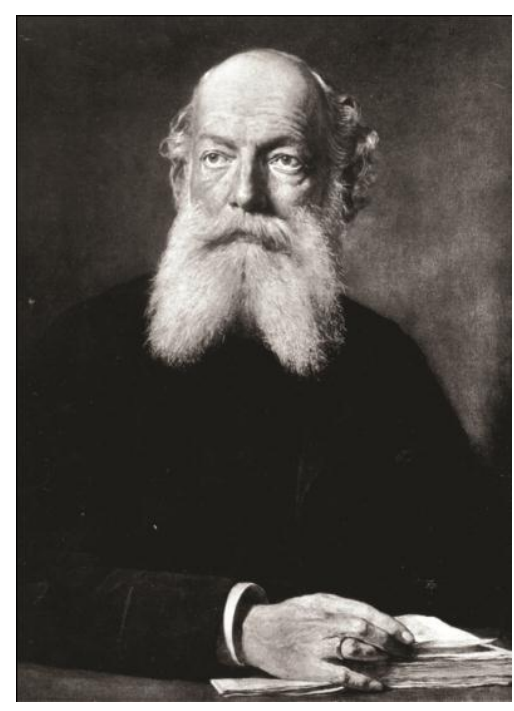

Figure 7. Friedrich August Kekulé (1829-1896). (Courtesy of the Edgar Fahs Smith Collection, University of Pennsylvania)

also advanced the theory of valence. ${ }^{[18]}$ These ideas were diffused, however, and what was needed was a unified theory to bring them together and explain atomic valence and molecular structure. The beginning of this clarification and theory came in the form of a number of publications in the late 1850s and 1860s. Among them were two theoretical papers from Kekule that appeared in 1857 and $1858{ }^{[19]}$ It is his second publication that most historians agree upon as the one signaling most clearly the birth of his theories. In it he crystallized with more clarity the generalizations he made in his earlier publications of the theories and ideas regarding structure. Acknowledging the contributions of Williamson, Odling and Gerhardt, Kekule emphasized the need to go beyond the groupings and down to the atomic level in considering molecular structure, and included a description of the nature of carbon, its tetravalent character (tetratomic or tetrabasic), and its ability to form bonds to itself. The third and most thorough elaboration of Kekulé's thoughts on structure are found in his famous textbook that appeared in parts during the period 1859-1866 (vols. 1 and 2 each comprised of three fascicles; this work continued afterwards as Chemie der Benzolderivate oder der Aromatischen Substanzen). It was in the pages of this book that Kekulé's "sausage" structures appeared for the first time. ${ }^{[6]}$

Kekule's contributions to the theory of structure were immediately and, with few exceptions, broadly accepted, but, as expected, controversies also arose regarding priority and credit. These controversies included the case of Scottish chemist Archibald S. Couper (1831-1892), who published a paper ${ }^{[20]}$ one month after Kekulé's landmark 1858 paper appeared that contained strikingly similar ideas to some of those found in the latter paper. Kekulé's fame and earlier publication clearly contributed to him receiving the lion's share of credit for these ideas, however. The Russian Alexandr Butlerov (1828-1886) is another chemist who is now credited with similar ideas on structure to those of Kekulé but received little, if any, recognition for them at the time. ${ }^{[6]}$ The Austrian Joseph Loschmidt (1829-1895) published a book in $1861^{[21]}$ with ring structures for benzene and some of its derivatives similar to those proposed by Kekulé, but their significance as anticipating the latter have been debated and regarded as misunderstandings. ${ }^{[6]}$

In addition to the above considerations, there were other events that featured prominently and synergistically to the solution of the atomic weights conundrum and the emergence of the structure of the molecule. ${ }^{[6-8]}$ The transition from the Lavoisierian provisional status of the elements until further decomposition to the Daltonian indivisible atoms corresponding to the different elements meant constant atomic weights. Ultimate atoms were unchanging but their content in their compounds in relation to other atoms could vary, with small whole numbers preferred in these combinations. At about the same time as Dalton's atomic theory appeared, GayLussac first observed that oxygen and hydrogen formed water by combining in the ratio of $1: 2$ by volume and then turned his discovery into the general law of combining volumes of gases, a counterpart to the law of multiple proportions for analysis and combination by weight as proposed by Dalton. The two laws, the former based on volumetric analysis and the latter on gravimetric analysis, provided an important clue to enlightment, but there was no way to reconcile them into a unified theory. In 1811, the Italian chemist Amedeo Avogadro (1776-1856) (Figure 8) published a paper (in Italian) in the Journal de Physique in which he provided an explanation of Gay-Lussac's law of combining volumes. In what is now known as the Avogadro hypothesis, he stated that equal volumes of gases at the same temperature and pressure contain equal numbers of particles (atoms or molecules). This meant that combinations by volumes in ratios of small whole numbers corresponds to combinations by paricles in ratios of small whole numbers, an insight that reconciled Dalton's law of multiple proprotions with Gay-Lussac's law of combining volumes. This conclusion was not, however, appreciated by the chemistry community until several years later. Some attribute this delay in understanding the significance of the Avogrado hypothesis to the 
low profile of the journal (in chemistry circles), and the language in which it was published. But the main reason, as claimed by Trevor H. Levere in his book Transforming Matter ${ }^{[8]}$ may lie in the axioms of the indivisible atom and the forbidden combination of atoms of the same element insisted upon by Dalton, whose influence was supreme during the first half of the nineteenth century.

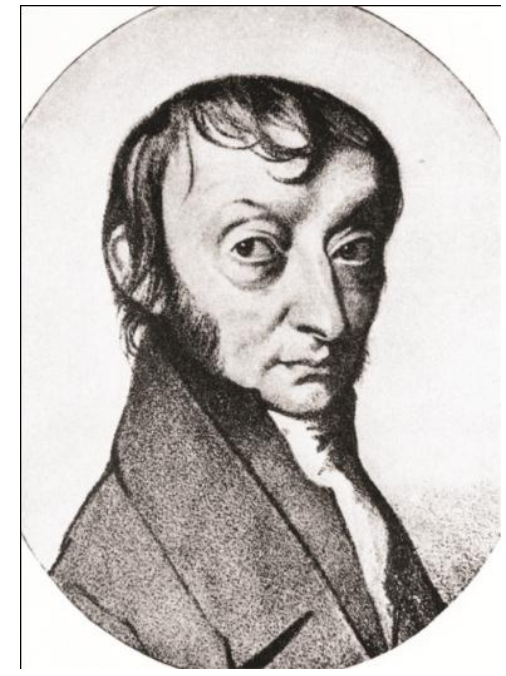

Figure 8. Amedeo Avogadro (1776-1856). (Courtesy of the Edgar Fahs Smith Collection, University of Pennsylvania)

While his indivisible atom principle was correct and appropriately held, Dalton's axiom that did not allow for like atoms to combine in diatomic molecules (i.e. two oxygen or two hydrogen atoms to combine in diatomic molecules of oxygen and hydrogen, respectively) was an obstacle to accepting Avogadro's ideas at an earlier time. Furthermore, these ideas contradicted the theories of another influential figure, Berzelius, on electrical dualism that also did not favor combinations of like atoms. Among those who dared go against Berzelius' doctrines were Gerhardt and Laurent, who followed the Avogadrian philosophy and used combining volumes rather than relative combining weights and equivalents. They inferred the diatomic nature of oxygen and hydrogen that eventually proved so fundamental in defining atomic weights. Gerhardt and Laurent's ideas gathered momentum after the death of Berzelius in 1848. To the gradual acceptance of these ideas and of Avogadro's hypothesis, the contributions of another Italian and student of Avogadro, Stanislao Cannizzaro (1826-1910) (Figure 9), would be most crucial. His first serious foray into the debate came in 1858 in the form of his publication titled "Sketch of a Course in Chemical Philosophy,"[22] in which he championed Avogadro's ideas and advocated a return from equivalents back to modified atomic weights. In his publication he stated, "The atomic weight of an element is the least weight of it present in the molecular weight of any of its compounds." By the end of the 1840s all looked ripe for resolution, but first all concerned parties needed to come together in body and mind. ${ }^{[6-8]}$

Kekule conceived the idea of an international conference to discuss contemporary issues of chemistry in 1859, and with the enthusiastic endorsement of Wurtz, organized what became the Karlsruhe Conference, one of the most historic gatherings of chemists ever held before or since. Held September 3-5, 1860, in the German town of Karlsruhe, this congress was attended by 146 chemists from 11 countries. Some declined to attend, registering their opposition to Kekulé and disagreement with what they suspected he and his supporters would propose. At Karlsruhe Kekulé, as expected, and Cannizzaro dominated the discussions.

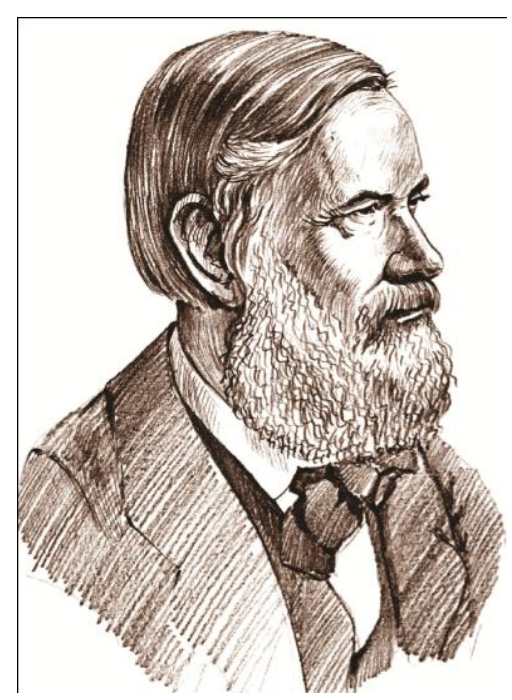

Figure 9. Stanislao Cannizzaro (1826-1910). (@iStockphoto.com, denisk0)

The latter vigorously advanced his ideas based on Avogadro's hypothesis and expressed two years earlier in his publication, and proved most compelling and influential. Kekulé differentiated atoms from molecules but was cautious not to equate chemical molecules with physical molecules as in the kinetic theory of gases, leaving certain ambiguities still unresolved. It appeared that Kekulé and Cannizzaro were "quibbling over trivial differences" as Wurtz put it, but in the end there was universal agreement on Cannizzaro's arguments on atomic and molecular magnitudes based on both chemical and physical data. But although Cannizzaro's performance at Karlsruhe was decisive, the outcome of the conference was the result of the gradual reform that took place during the prior decades of the nineteenth century, starting with Dalton, Gay-Lussac, Avogadro, Berzelius, and the French-English school of Gerhardt, Laurent, Wurtz, Williamson, Odling, and others. Rocke ${ }^{[6]}$ described the events at Karlsrule as follows:

"The contending armies that met at Karslruhe were the atomists and the greatly underrepresented equivalentists. The war, however, was already virtually won. Gerhardt and Laurent had been advocating since 1842 essentially the Berzelius atomic weight system modified to achieve consistent molecular magnitudes. Williamson joined their camp in 1849, Odling and Kekulé in 1854. Wurtz and Hofmann both advocated the conceptual reform from about 1850 , though Wurtz only began using atomic weight notation in 1859 and Hofmann in 1860 . By the time of the call to Karlsruhe, the equivalentists were in retreat, as is clearly revealed in the response of Kolbe and Berthelot to that call. Even those who continued to use equivalent formulas, such as Liebig and Gmelin, believed in the truth of the atomic theory. The outcome of the vote on the resolution henceforth to use only the reformed atomic weights in formulas was a foregone conclusion."

In addition to the agreement on atomic weights and chemical formulas, the Karlsruhe conference approved a resolution on equivalents, which, however, left certain ambiguities and confusion 
that would linger until later when the theory of valence was clarified and took hold.

One of the attendees of the Karlsruhe conference was young Russian Dmitri Mendeléev (1834-1907) (Figure 10), who later developed the first periodic table of elements which was subsequently revised several times and evolved into today's periodic tables. This development was one of great significance to understanding, systematizing, and advancing chemistry, not to mention teaching it. One of the result of this development was that several elements were predicted to exist and later discovered to fill the original blanks in the periodic table. Another was the prediction of properties of the various elements depending on their position on the periods table.

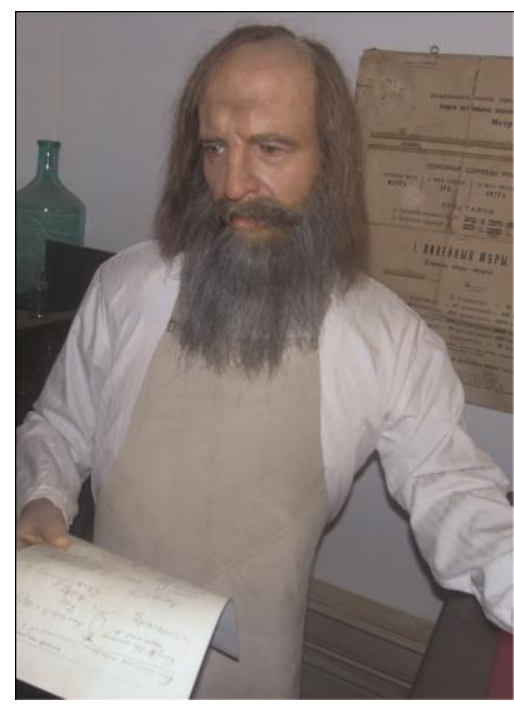

Figure 10. Dmitri I. Mendeléev (1834-1907). (Photo by K.C. Nicolaou, the Vodka Museum, St. Petersburg, Russia)

In 1865, Kekulé published the ring structure of benzene more or less as we know it today, ${ }^{[23]}$ later claiming a dream as his inspiration for the hexagonal depiction. He also introduced other graphical formulas with tetravalent carbon atoms and bonds to other atoms. Together with the Karlsruhe conference's conclusions, this seminal publication signaled a new epoch for organic chemistry, one that would revolutionize research in both academic and industrial laboratories with all the benefits to science and society that we came to know ever since. In summarizing the events that led to the structural theory from 1840 onwards Kekulé later wrote:

"Fifty years ago the river had divided into two branches; one flowed mostly on French soil through luxuriant fields of flowers, and those following it, led by Laurent and Dumas, could reap rich harvests along the entire journey almost without effort. The other followed the direction indicated by the long established and approved guidepost erected by the great Swede Berzelius. It led mostly through broken boulders, and only later returned to fruitful land. Finally, when both branches had approached quite close to each other, a thick underbrush of misunderstandings still separated them. The groups of travelers did not see each other, nor did they understand the others' language. Suddenly a loud cry of triumph rang out in the camp of the type theorists. The others had also arrived, Frankland at their head. It was now seen that both had had the same goal, even if they had traveled different paths. Experiences were exchanged; each party gained advantage from the achievements of the other, and with united forces the travelers continued their journey on the reunited river, through the most fertile fields. Only a few held themselves apart and sulked; they thought only they had followed the right path, only they were in navigable waters; but they still followed the current." ${ }^{[6]}$

Kekulé was lionized and his contributions celebrated and hailed as the foundation of modern organic chemistry at a festive banquet (Benzolfest) held in Berlin in 1890.

The use of the bond theory in combination with the tetravalence of carbon became known as the structural theory of organic compounds. Organic chemistry was well on its way to becoming rational and structure based. Something important, however, was still missing: the three-dimensional arrangement of atoms within the molecule.

The phenomenon of molecular handedness, later termed chirality, would play an important role in the next developments in the structural theory. Its history began with the investigations of the Frenchman Jean-Baptiste Biot (1774-1862) with quartz crystals which, being helical, exhibited chirality, manifesting itself through the property of optical rotation. Soon, Biot discovered optical activity in several organic compounds of natural origin. Louis Pasteur (1822-1895), Biot's student, discovered the two enantionmeric forms of tartaric acid crystals. He separated them by hand under the microscope and showed them to rotate polarized light by the same extent in opposite directions. Lactic and tartaric acids, both isolated for the first time by Scheele, were found by Berzelius and Biot, respectively, to exist in two different forms-one exhibiting optical activity and another which did not. Biot named the optically inactive tartaric acid as racemic acid, from the Latin racemus -meaning 'cluster of grapes', from where it was isolated. Biot had already recognized that, unlike quartz, organic compounds retained their optical rotation after they have been melted or dissolved, meaning that the property was inherent to their molecular structure and not due to the structure of a molecular aggregate such as a crystal. ${ }^{[4,6,8]}$

The next advance would come from Jacobus van't Hoff (18521911) and Joseph Le Bel (1847-1930), both of whom were students of Wurtz in Paris. In 1874, van't Hoff and Le Bel advanced the concept of a tetrahedral carbon with its four valencies (or bonds) pointing to the four corners of the tetrahedron where the four substituents were situated. This arrangement, with four different substituents, would explain the origin of molecular 'handedness' or chirality. The hypothesis was convincing, except to Kolbe, who raised his objections just as he did before against the French school's theories and Kekulé's views on structure. If true, this theory would provide the proof for the structural basis of molecules as ordered collections of atoms bonded together in specific arrangements. ${ }^{[8]}$ Slowly the complete structural theory began to take hold, although the final proof would only come later with the advent of X-ray crystallography. van't Hoff would go on to become the first Nobel Laureate in Chemistry (1901). The citation, however, for his Nobel Prize was "in recognition of the extraordinary services he has rendered by the discovery of the laws of chemical dynamics and osmotic pressure in solutions," rather than stereochemistry, a sign of the skepticims about van't Hoff's theory at the time.

The graphical structural formulas gave a huge impetus to organic chemistry, particularly organic synthesis where chemists would write the formula of a compound on paper or the blackboard and go into the laboratory and synthesize it, appreciating which bonds were made and which were broken. Predictions of reaction outcomes could be made and confirmed through experimentation. Organic chemistry could be taught on a rational basis and synthetic 
designs would lead to powerful processes for the production of chemicals, natural or designed. The last decade of the nineteenth century witnessed a dramatic expansion of the chemical industry, particularly the dyestuffs and pharmaceutical industries-all due to the theoretical contributions of the likes of Kekulé, van't Hoff and Le Bel that revealed the structure of the molecule as in benzene and its derivatives and the tetrahedral arrangement of carbon.

The twentieth century ushered in enormously important advances in theoretical chemistry that led to an even better understanding of the chemical bond and the structure of the molecule. These advances were made possible by the advent of quantum mechanics, a theory that originated from physics through the works of many, including the likes of Max Planck (1858-1947), Albert Einstein (1879-1955), Werner Heisenberg (1901-1976), Niels Bohr (1885-1962), Max Born (1882-1970), Louis de Broglie (1892-1987), Erwin Schrödinger (1887-1961), John von Neumann (1903-1957), Wolfgang Pauli (1900-1958) and Paul Dirac (19021984), among others.

Among the many who infused and employed quantum mechanics in chemistry, it was Linus C. Pauling (1901-1994), ${ }^{[24,25]}$ chemist-physicist-mathematician, who had the most profound influence in the field that emerged through this fusion of physics and chemistry. In his legendary book The Nature of the Chemical Bond ${ }^{[26]}$ first published in 1939, Pauling articulated his ideas on the electron sharing by atoms, electron orbital hybridization, nature of the chemical bond, resonance, electronegativity, ionic and covalent bonds, van der Waals bond, aromaticity, the structure of benzene, and the hydrogen bond, among other pressing questions of his time. ${ }^{[24-26]}$ His insights combined with the contributions of other preeminent physical chemists of the time, including G. N. Lewis (1875-1946), Irving Langmuir (1881-1957), Robert Mulliken (1896-1986), and Erich Hückel (1896-1980) provided the foundation onto which the science of chemistry, and much of biology, was built in the latter decades of the twentieth century. Refined and developed further, ${ }^{[27]}$ quantum theory aided immensely the advances made in experimental chemistry and biochemistry, including chemical synthesis and structural biology, and provided predictions and explanations of countless chemical phenomena. Pauling won two Nobel Prizes, the first for Chemistry (1954, "for his research into the nature of the chemical bond and its application to the elucidation of the structure of complex substances") and the second for Peace (1962).

\section{Natural Products, Organic Synthesis and Total Synthesis}

Organic chemistry made its first steps in the second half of the eighteenth century with Lavoisier in France and Scheele in Sweden, providing the first foundations with their initial discoveries and philosophies. Considered by many to be the father of natural products chemistry, Scheele discovered numerous natural products of the acid type through his invented and improved laboratory techniques that included acid-base salt formation, salt decomposition, and extraction. His acid discoveries were soon followed by the discovery of the first naturally occurring base or 'alkaloid' from nature, namely morphine. The apothecaries JeanFrancois Derosne (1779-1855) and M. Armand Séguin (1767-1835) in Paris and Friedrich Sertürner (1783-1841) in Germany first isolated a salt of morphine from opium in 1805. Sertürner recognized that the original isolate was a salt and went on to isolate the base, or 'vegetable alkali' as he called it. Soon, a whole new family of alkaloids would be discovered in Paris, with Louis Nicolas Vauquelin (1763-1829) and Gay-Lussac and their students leading the way in this new pursuit. Among the other most famous alkaloids to be discovered in the early part of the nineteenth century would be quinine and strychnine, more about which we will discuss later.

Isolated from human urine by Hilaire M. Rouelle (1718-1779) in 1773 , urea was to play a major role in the history of chemistry, for, in the minds of many organic chemists, its laboratory synthesis from ammonium isocyanate by Wöhler (Figure 11) in 1828 marked the birth of organic synthesis, ${ }^{[28]}$ serendipitous as it was (some view the synthesis of acetic acid as the true beginning of organic synthesis, see below). This was not only an early example of the phenomenon of isomerism (between ammonium isocyanate and urea) but, more importantly, it demonstrated vividly that man can create nature's molecules of life, although there had been earlier instances of laboratory syntheses of simple organic compounds. This was how, from the 1793 definition of chemistry as "the science of analysis" by Lavoisier, emerged, a few decades later, the new branch of this science, chemical synthesis, as described by Marcellin Berthelot (1827-1907) in 1860: ${ }^{[29,30]}$

"Having completed his analytical work, the chemist proposes to re-compose what he has destroyed; he takes as his point of departure the ultimate of analysis, i.e. simple bodies, and he compels them to unite with each other and by their combination to re-form the same natural principles which constitute all material beings. Such is the object of chemical synthesis." ${ }^{\text {,29] }}$

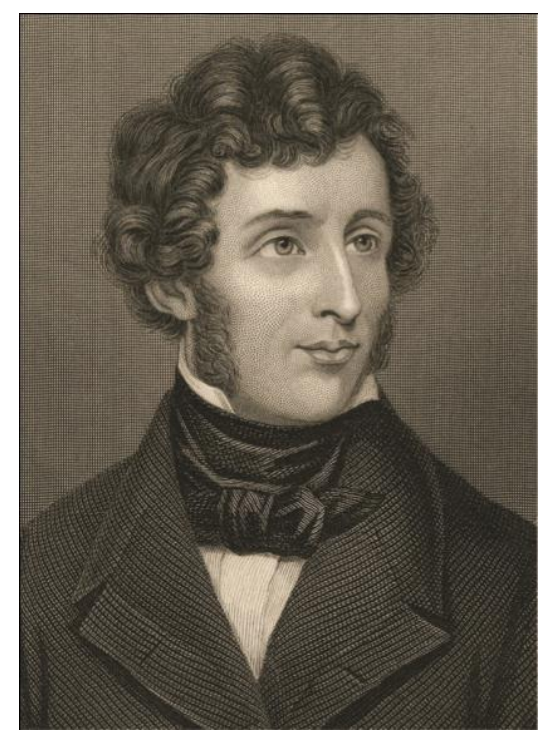

Figure 11. Friedrich Wöhler (1800-1882). (Courtesy of the Edgar Fahs Smith Collection, University of Pennsylvania)

Later, this general building description of synthesis was more precisely defined to include a number of more specific operations, ${ }^{[29]}$ namely: a) formation of a natural organic product from any other simpler natural product; $b$ ) formation of a natural organic product from an artificial product; c) formation of a natural organic product from the elements directly; d) formation of an artificial organic product from any other artificial product; e) formation of an artificial organic product from the elements directly; and $f$ ) formation of an artificial organic product from a natural one of simpler structure. Today, all these descriptions can be encapsulated into an expanded definition of synthesis to convey the meaning of constructing a chemical compound from other 
compound(s) and/or element(s). Organic synthesis refers to the construction of the compounds of carbon, particularly those found in living systems.

Three years before the momentous preparation of urea by Wöhler, Liebig (Figure 12) was appointed Professor of Chemistry at Giessen. For the next 28 years he led a revolution in organic chemistry impressive not only for the number of organic compounds analyzed and synthesized, but also for the number and preeminence of disciples that emerged from his school of chemistry. Liebig's students spread the science of organic chemistry and organic synthesis throughout Europe. He brought elemental analysis of organic compounds to new levels of accuracy by his potash apparatus that measured the amount of carbon dioxide produced from a compound on combustion. Some of the most famous natural products of the time, including morphine, quinine and strychnine, were analyzed in his laboratory. Most importantly, Liebig brought unprecedented respectability to chemistry and introduced the teaching laboratory model, with the professor being the group leader of several students working and learning in the laboratory under his mentorship. Still used today around the world, this model was exported to other countries, including England and America, where it made an enormous impact in training and productivity. Liebig advanced and promoted organic synthesis decisively, particularly the chemistry of benzene derivatives. ${ }^{[6,8]}$

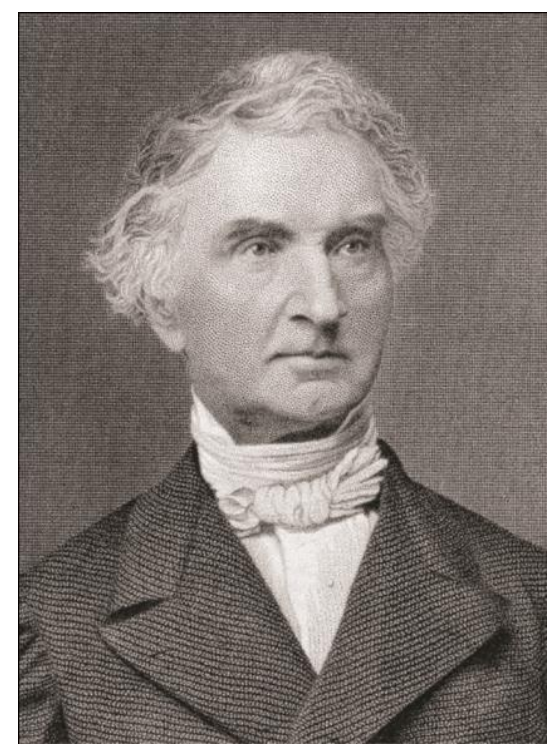

Figure 12. Justus von Liebig (1803-1873). (Courtesy of the Edgar Fahs Smith Collection, University of Pennsylvania)

One of Liebig's most successful students was A. W. von Hofmann (Figure 13) who was brought to London in 1845 by Queen Victoria to head the newly established Royal College of Chemistry. There, Hofmann and his students were actively investigating the chemistry of aromatic compounds such as aniline, which they obtained from benzene by nitration and reduction. Myriad benzenoid derivatives were thus synthesized in Hofmann's London laboratory, prompting him to proclaim proudly, "Gentlemen, new bodies are floating in the air," as a new reaction was added to the list. This was organic synthesis at the time, an empowering new endeavor within chemistry, as its practitioners were finding out.

In 1845 Kolbe synthesized acetic acid, ${ }^{[31]}$ essentially from elements and water, demonstrating one of the first examples of carbon-carbon bond formation. The synthesis of acetic acid, a naturally occurring substance with a $\mathrm{C}-\mathrm{C}$ bond was an important milestone after Wöhler's synthesis of urea, the latter containing only one carbon atom in its structure. Indeed, many authorities consider Kolbe's deliberately planned synthesis of acetic acid as the starting point of organic synthesis, rather than Wöhler's fortuitous synthesis of urea from ammonium isocyanate. Kolbe would later on synthesize salicylic acid, an important fragment of the naturally occurring salicin and a precursor to acetyl salicylic acid (Aspirin ${ }^{\circledR}$ ).

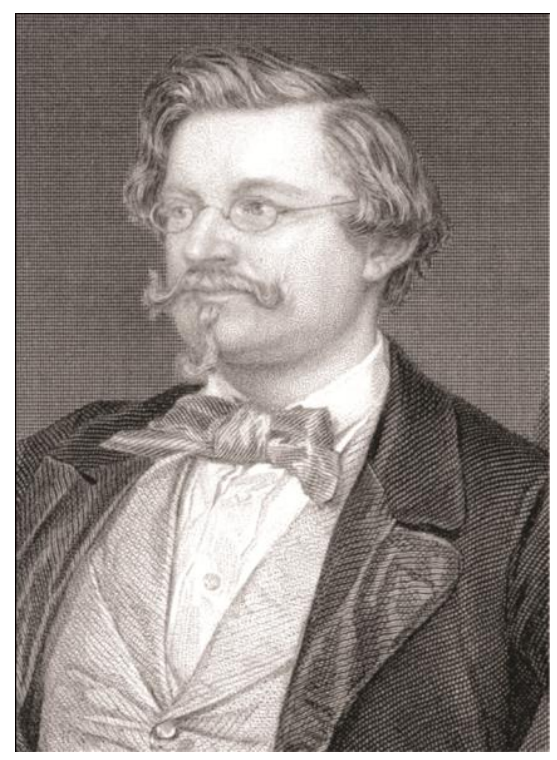

Figure 13. August Wilhelm von Hofmann (1818-1892). (Courtesy of the Edgar Fahs Smith Collection, University of Pennsylvania)

In the second half of the nineteenth century, organic synthesis played a major role in establishing entirely new industries such as the dye industry and the pharmaceutical industry. Thus, in 1856, William Henry Perkin, Sr. (1838-1907), prompted by his teacher Hofmann to attempt the synthesis of quinine, discovered mauve, the first dyestuff, by oxidizing toluidines with chromic acid. Quinine was first isolated in 1820 from the bark of Cinchona officinalis L. (quina quina) by the French pharmacists Pierre-Joseph Pelletier (1788-1842) and Joseph-Bienaimé Caventou (1795-1877) as a result of their efforts to identify the active ingredient of cinchona that cured malaria. Hofmann's rather naïve recommendation to use toluidines as starting materials for quinine based on the latter compound's empirical formula $\mathrm{C}_{20} \mathrm{H}_{24} \mathrm{~N}_{2} \mathrm{O}_{2}$, reflects the lack of structural understanding of the molecule at the time, and amplifies its importance of structure to organic chemistry in general and organic synthesis in particular. Be that as it may, this "naivaté" led to a most important, albeit serendipitous discovery, that of the first artificial dyestuff (mauve, mauveine). Many more dyestuffs were soon discovered and synthetic dyes became popular and cheaper alternatives to naturally derived coloring materials. In 1862, Hofmann declared with confidence:

"England will, beyond question, at no distant day, become herself the greatest colour-producing country in the world; nay, by the strangest of revolutions, she may, ere long send her coalderived blues to indigo-growing India; her tar-distilled crimson to cochineal-producing Mexico, and her fossil substitutes for quercitron and safflower to China, Japan, and the other countries whence these articles are now derived." ${ }^{[29]}$

This prophecy would not really be fulfilled, however, for it was Germany that took the lead in the dye manufacturing. This was 
made possible by the systematic education and training of synthetic organic chemists who took the lead in the discovery and industrial production of these valuable materials. Alizarin, indigo and many other dyestuffs were produced by chemical synthesis, no less than 12,000 of them by the year 1900. Adolf von Baeyer (1853-1917), born Johann Friedrich Wilhelm Adolf Baeyer, played a protagonist role in the advancement of organic chemistry in general and the dye industry in particular in Germany in the second half of the nineteenth century. Among his numerous contributions was the total synthesis and structural elucidation of indigo, a naturally occurring and popular, at the time, coloring material. Baeyer also synthesized many other dyes and coloring substances such as alizarin, Congo red, phenolphthalein and fluorescein. ${ }^{[29,32]}$

Soon after the dyestuffs, pharmaceuticals began to emerge from the laboratory through organic synthesis, although overshadowed in the early days by dyes. The pharmaceutical industry would later thrive to unimaginable, at the time, levels of production and impact on society. Introduced in 1899 by the Bayer company, Aspirin ${ }^{\circledR}$ is the first and perhaps the quintessential example of a drug discovery effort based on a natural product lead, salicin, a paradigm which is still valid today. ${ }^{[10]}$

In the meantime, the state of the art of synthetic organic chemistry had advanced to powerful technology ${ }^{[29]}$ employing routinely versatile reagents such as acetoacetic and malonic esters introduced by Frankland and Duppa and by Max Conrad, respectively. Famous condensations such as Claisen, Knoevenagel, and Michael, among others, were discovered. Heterocycle forming reactions named after Baeyer, Knorr, Skraup and Hantzsch were also discovered and developed, and so were the organometallic reagents of Barbier and Grignard. Other important reactions discovered in the early twentieth century era included the FriedelCrafts and Diels-Alder reactions, as well as the "aldol reaction", commonly cited anonymously, but which should be credited to Wurtz and Borodin, who discovered it independently. A. W Hofmann had at least three such reactions named after him-the Hofmann degradation, the Hofmann elimination, and the Hofmann rearrangement reaction. ${ }^{\text {[29] }}$

Adding to the significance of organic synthesis was its ability to establish the chemical structures of natural products, a role that began to emerge in the latter part of the nineteenth century. By the dawn of the twentieth century it was accepted that structural evidence coming from synthesis was at least as valid as the arguments coming from degradation, the latter once thought of as the ultimate task and structural proof. ${ }^{[29]}$ In $1905^{[29]}$ Ladenburg underscored that "the synthetical method constitutes a necessary complement" to the older "analytical procedures", and referred to numerous syntheses of naturally occurring substances, including those of alanine (Strecker, 1850), mustard oil (Zincke, 1855), glycine (Perkin and Duppa, 1858), guanidine (Hofmann, 1861), choline (Wurtz, 1867), vanillin (Reimer and Tiemann, 1878), allantoin (Grimaux, 1877), tyrosine (Erlenmeyer, 1883), indigo (Baeyer, 1870), and coniine (Ladenburg, 1886). Here we must add the syntheses of glucose (H. E. Fischer, 1891), salicylic acid (Kolbe, 1859), camphor (Komppa, 1903), and terpineol (W. H. Perkin, Jr., 1904), all of which have been achieved before 1905. ${ }^{[10]}$

In 1907, the great German chemist H. Emil Fischer (18521919), referring to the future of organic synthesis, wrote:

"Laboratory synthetic methods will be indispensable for a long time to come, not only for preparative purposes but also as the means of elucidating the structure of complex substances of natural origin." [29]
This statement rings true even today ${ }^{[33]}$ in several instances despite all our advantages of physical methods and instrumentation.

In 1860, Marcellin Berthelot published a book titled Organic Chemistry Founded on Synthesis, in which he articulated synthesis as the ultimate weapon against the doctrine of vitalism. ${ }^{[30]} \mathrm{He}$ synthesized primarily hydrocarbons and alcohols, some in extremely low yields and of no practical value, and attempted to show that the principal forces operating in mineral and organic chemistry are the same. Some believe that his synthetic campaign had ideological motivations, nevertheless his contributions to organic chemistry were highly important. ${ }^{[29]}$

Synthesis has also been used to test fundamental hypotheses of theoretical interest. Such cases include the synthesis of small carbocyclic rings by W. H. Perkin, Jr. (1860-1929), in order to test Baeyer's strain theory that prohibited their existence, and Leopold Ruzicka (1887-1976) and Max Stoll's synthesis of macrocycles in contradiction to strain theory but in harmony with Ruzicka's conviction that ciretone possessed a 17-membered carbocyclic ring. ${ }^{[29]}$ Another example of synthesis carried out as part of a strategy to study theoretical predictions is F. Sondheimer's (19261981) synthesis of annulenes, which led to the confirmation of Hückel's rule of aromaticity and several fundamental insights on the subject.

Despite its successes and huge contributions, there is no denying that organic synthesis had its critics from time to time. One of the earliest was W. A. Stewart, who wrote in 1918:

"Despite the Brierean efforts of the synthetic school, it is safe to say that the latter half of the nineteenth century will be regarded as a time when theoretical speculation played the main part in the development of the subject. Of the hundred thousand organic compounds prepared during that time, the majority were stillborn and their epitaphs are inscribed in Beilstein's Handbook. Compared with great clarifying process which laid the basis of our modern views, they weight but little in the balance...During the last 50 years the flood of synthetic material, principally from German laboratories, has tended to obscure the genesis of what we still, after respect for tradition, term organic chemistry." "[29]

Given the momentous discoveries and inventions emanating from synthetic laboratories before and since, this rather severe criticism of synthesis is unjustified.

The role of natural products in the development of organic synthesis in particular, and organic chemistry in general, cannot be emphasized enough. Two early, but prominent examples of influential natural products are urea and strychnine. ${ }^{[10]}$ Thus, the discovery of strychnine in 1818 by the Frenchmen Pelletier and Caventou from the seeds of the strychnos ignatii tree and the synthesis of urea by Wöhler in 1828 had a major impact on the emergence and evolution of organic chemistry. Thus, while the latter event marked the advent of organic synthesis, the former contributed, through the challenges of its structural elucidation and total synthesis, to the expansion of its reach. Both events had an enormous influence on the entire field of organic chemistry. Indeed, and as Leo B. Slater articulates in a compelling manner, ${ }^{[34]}$ strychnine's history provides a roadmap from which to view the evolution of the scope of organic chemistry and the power of organic synthesis in terms of molecular structure determination and depiction. Thus, early medical interest in the seeds of Strichnos ignatii prompted the isolation of the compound, which then led, through elemental analysis, to the determination of its empirical formula by combustion methods which were already known and 
undergoing development at the time. The next questions, those of the actual molecular formula and structure of strychnine, were not even possible to consider until after the structure theory took hold in the 1860 s and 1870s. It was not until the last decade of the nineteenth century that serious work on the structure of strychnine began, primarily by the Swiss-born chemist Julius Tafel (18621918). Following these early studies, several schools contributed to the strychnine problem. Among them the most prominent were those of Hermann Leuchs (1879-1945), Vladimir Prelog (1906-1998), Robert Robinson (1886-1975), Heinrich Wieland (1877-1957), and Robert Burns Woodward (1917-1979). ${ }^{[34]}$ Leuchs and Robinson contributed the most toward the elucidation of the coveted structure which was depicted at the time not to reflect the reality as we perceive it today, but rather as short-hand information regarding possible connectivities based on the chemistry performed on the natural product. The final answer to the actual structure of strychnine came in 1946 and 1947 when, first, Robinson published (1946) two possible structures in Nature ${ }^{[35]}$ based on all the chemical information gathered up to that point and, then, Woodward reported (1947) in the Journal of the American Chemical Society ${ }^{[36]}$ the singularly unique structure of strychnine-one of the two reported by Robinson-which was not only based on all the chemical data known for strychnine at the time, but also confirmed by UV spectroscopy (comparison of the UV properties of the natural product with appropriate synthetic model systems). In addition to tracing the history of structural elucidation, the architecturally beautiful structure of strychnine served to challenge synthetic organic chemists ever since it became known. Thus, beginning with Woodward's landmark total synthesis published in $1954,{ }^{[37]}$ there have been numerous total and formal syntheses reported. A recent review by Cannon and Overman ${ }^{[38]}$ places these syntheses in perspective, underscoring the improvements made in reaching this target through the ever-increasing power of new synthetic methods and strategies. Woodward's collection of total synthesis achievements, ${ }^{[39]}$ besides strychnine, include quinine, sterol, lysergic acid, reserpine, chlorophyll, cephalosporine, and vitamin $\mathrm{B}_{12}$. The latter represented the most complex molecule to be synthesized in the laboratory at the time of its synthesis (1973-1976), a feat accomplished in collaboration with Albert Echenmoser (born 1925). ${ }^{[10]}$

The last aspect of Woodward's detective work on the structure of strychnine was not only crucial for the final solution of the problem but more importantly it marked a sharp transition for both structure elucidation and organic synthesis into a new epoch. The new era was brought about by an array of technological advances in instrumentation that brought closer together structural representations with real materials and their properties. ${ }^{[0]}$ This reification was realized through physical data collected by machines such as infra red (IR), ultra violet (UV), mass spectrometry (MS), NMR spectroscopy, and X-ray crystallography instruments. The plethora of data on large numbers of compounds allowed for generalizations and rules that facilitated enormously structural elucidations of natural and synthetic compounds and, to some extent, made obsolete the methods of analysis of the past, namely elemental analysis, degradation, and reactivity. Furthermore, this instrumentation-based revolution that took hold in the 1940s and 1950 s and grew dramatically in the subsequent decades made possible the representation of complex molecules in three dimensions, permitted reactivity and stereoselectivity outcomes to be predictable, and allowed reaction mechanisms to flourish as tools for designing and explaining chemical reactions with rationale and reliability. Woodward was at the right place at the right time to use and champion this dramatic change. He contributed to the emergence of several rules such as the "Woodward Rules", the "Octant Rule", and the "Woodward-Hoffman Rules". He was also the chemist who led the new revolution in total synthesis that became possible and which was facilitated greatly by the instrumentation revolution after World War II. During the new era the attention of organic chemists turned dramatically toward the synthesis of the natural product rather than its structural elucidation, since the latter could now rely on machines. ${ }^{[40]}$ This focus, however, did not diminish the importance of isolation and structural determination of natural products, as these endeavors require exquisite diligence and ingenuity and are inspirational to chemists and biologists alike.

Indeed, the success of the penicillin ${ }^{[10]}$ as an antibiotic gave impetus to chemists in the pharmaceutical industry and academic institutions to search for, and discover a number of other revolutionary medicines from nature. Their impact on healthcare is beyond measure as reflected in the fact that today the majority of clinically used drugs are directly or indirectly originating from nature. These new molecules, architecturally beautifully crafted by nature, as they were, fascinated and challenged a new generation of organic chemists, now called practitioners of total synthesis, who for the last half century or so produced much new science and technology in chemistry, biology, and medicine with remarkable speed and benefits to society. ${ }^{[41]}$

The Woodward era was followed by an even more impressive period of expansion led by Elias J. Corey (born 1928), the new genius on the scene who was appointed at Harvard in 1959 as a professor of chemistry. ${ }^{[12]} \mathrm{He}$ turned the art of synthesis into a science through the development of the theory of retrosynthetic analysis and rational strategy design. His extraordinary contributions to the field of chemical synthesis also include the total synthesis of numerous natural and designed molecules such as longifolene, gibberilic acid, aplasmomycin, the prostaglandins and leukotrienes, erythronolide $\mathrm{B}$, ginkgolide $\mathrm{B}$, maytansine, and ecteinascidin, just to mention a few, and the introduction of many new reactions, reagents, and catalysts for practical asymmetric synthesis. In addition to these contributions, Corey's important influence extends into the realm of biology and medicine by connecting natural products synthesis to biological investigations and medical applications. This integration is demonstrated with his classical work on the synthesis of prostaglandins and leukotrienes whose natural scarcity prohibited their full biological investigation until they were synthesized in the laboratory in sufficient quantities. His work also demonstrated and inspired natural product analog design and synthesis for the purpose of biological investigations ${ }^{[42]}$ as well as process development for large scale production of pharmaceuticals. These practices became increasingly integrated within total synthesis endeavors and today they constitute highly desirable, if not essential components of such research programs.

In addition to Corey's science shaping contributions, many other discoveries and inventions from numerous other investigators contributed to the dramatic advancements in the field of organic synthesis in recent decades. The Grignard reaction and the metal catalyzed hydrogenation of unsaturated organic compounds pioneered by the Frenchmen Victor Grignard (1871-1935) and Paul Sabatier (1854-1941), respectively, proved critical in this regard. The Diels-Alder reaction discovered by Otto P. H. Diels (18761954) and Kurt Alder (1902-1958) in 1928 is one of the most significant and enabling reactions ever discovered and developed for organic synthesis and has had an enormous and lasting impact on the field. Georg Wittig (1897-1987) and Herbert C. Brown (1912- 
2004) developed the use of phosphorus and boron-containing compounds for organic synthesis, respectively, thereby extending its reach. Important methods are also developed for the chemical synthesis of nucleotides and peptides, starting with the pioneering works of Har Gobind Khorana (1922-2011) and R. Bruce Merrifield (1921-2006), respectively. ${ }^{[32]}$

By the end of the twentieth century the practice of organic synthesis had changed dramatically. ${ }^{[11,12,41]}$ Asymmetric catalysis, palladium-catalyzed cross couplings, and the metathesis reaction were dominating the new synthetic methodology area and influenced the field of organic synthesis in unprecedented ways, precipitating major changes in the manner in which synthetic organic chemists were thinking about and practicing their science. This revolution in new synthetic methods was brought about by many practitioners around the world. Of particular impact to organic synthesis were the pioneering works of William S. Knowles (19172012), Ryoji Noyori (born 1938), K. Barry Sharpless (born 1941) and Henri B. Kagan (born 1930) in asymmetric catalysis; Yves Chauvin (born 1930), Robert H. Grubbs (born 1942), Richard R. Schrock (born 1945) and Thomas J. Katz (born 1936) in the metathesis reaction; and Richard F. Heck (born 1931), Ei-ichi Negishi (born 1935) and Akira Suzuki (born 1930) in the field of palladium-catalyzed cross couplings in organic synthesis. ${ }^{[1]}$

Besides enabling numerous other disciplines and endeavors, organic synthesis proved pivotal in realizing the scope and generality of key discoveries, thereby helping to establish entirely new fields of investigation. Such was the case of the discovery of 18-Crown-6 by Charles J. Pedersen (1904-1989), which was swiftly turned into the field of molecular recognition and supramolecular chemistry by Donald J. Cram (1919-2001), Jean-Marie Lehn (born 1939) and many other investigators through the design and synthesis of artificial ionophores and other binding molecules. The discovery of the fullerenes (buckyballs) made by Robert F. Curl, Jr. (born 1933), Sir Harold W. Kroto (born 1939) and Richard E. Smalley (1943-2005) in 1985 gave the opportunity to organic chemists to study their chemistry, thereby establishing an important branch of nanotechnology.

The discovery of the double helix, ${ }^{[43]}$ the most beautiful molecule of nature, provides yet another example of how organic synthesis can be employed to exploit new opportunities, in this case to design and synthesize nucleosides and oligonucleotides for various intents and purposes. These developments yielded untold dividends in fundamental science (e.g. etiology of nucleic acid structure $)^{[44]}$ and the pharmaceutical and biotechnology industries.

The sharp tools of organic synthesis have also been used to generate, in both industrial and academic laboratories, useful compound libraries with impressive molecular diversity. ${ }^{[4]}$ These collections of small organic molecules serve admirably as alternative sources of molecules from which lead compounds can be discovered through biological screening for optimization and development in medicinal chemistry and chemical biology investigations. New trends in pharmaceutical research and academic endeavors such as antibody drug conjugates, receptor identification, and diagnostic tools, demand large molecules consisting of assemblies of often several constructs. Organic synthesis is routinely called upon these days to assemble such molecules through the process known as conjugation or ligation. Such facilitating operations will continue to enable the biological sciences and penetrate new domains of science and technology, including materials science and nanotechnology.

Armed with its enhanced power, synthetic organic chemists began, in the last two decades, to move steadily from targeting the structure of the molecule to aiming for the function of the molecule. ${ }^{[46,47]}$ Research programs in total synthesis were expanded to encompass method development and chemical biology aspects related to the structural motifs and the biological properties of the targeted natural product and designed analogs of it. Today a total synthesis is appreciated and admired not only because of its aesthetically pleasing assimilation of known synthetic elements, but also for its delivery of new synthetic reactions and molecules of biological and medical importance.

Another recent phenomenon in the field of natural products is the increased emphasis on searching for marine bioactive compounds which, by necessity, are isolated in small amounts, thereby requiring chemical synthesis to enrich their supplies for thorough biological investigations. The overall number of truly novel structures isolated from natural sources, however, is currently on the decline, a trend that, if continued, will limit the choices and challenges for synthetic organic chemists. It will be, indeed, unfortunate if chemists are denied the enormous molecular complexity and diversity that still remains to be unraveled in the forests, the soils, and the oceans of the earth, for, as with the past, these molecules can provide us with precious knowledge, inspiration for mimicry, and unique opportunities for discovery and invention. ${ }^{[10]}$

\section{Conclusion and Future Perspectives}

From the ability of scientists to visualize the microcosm of atoms and molecules and to construct the latter from the former emerged an awesome power, that of creating new chemical entities in the laboratory, natural or designed, of all types and for all kinds of applications. Hitherto allocated to the domain of nature, organic synthesis came of age in the nineteenth century when both the structure of the molecule and the ability to synthesize it were discovered and recognized as fundamental to all material and life sciences. As a result of centuries of philosophizing, theorizing, and experimenting, these breakthroughs led to major discoveries and inventions in chemistry, biology, medicine, materials science and engineering. One measure of the power of organic synthesis at any given time is the state of the art of total synthesis, which, in turn, can be gaged by the complexity of the molecules it can reach and employ for various applications. Today, organic synthesis, in general, and total synthesis of natural products of biological and medicinal importance, in particular, are at the forefront of research within the molecular sciences. Indeed, and as articulated by $\mathrm{H}$. Waldmann in a recent editorial, ${ }^{[48]}$ the trio of organic synthesis, chemical biology, and drug discovery constitutes a formidable collaborative alliance in the pursuit of fundamental knowledge in the life sciences and its application to human health and well being.

Looking back, behind the misty shadows of the major discoveries and innovations that occurred in the nineteenth and twentieth centuries in chemistry, one can detect the controversies and missed opportunities of its practitioners. First are the inevitable quarrels among the protagonists as they attempted to claim priority for some of these discoveries. Second, and more importantly, are the opportunities missed by chemists who ignored the literature or events in other disciplines (e.g. the Avogrado hypothesis) or neglected to pay attention to interdisciplinary problems (e.g. the double helix). These realizations could perhaps serve as lessons for the future as chemists attempt to broaden the horizons of their science and educate the next generation of its practitioners. Looking ahead, and to be sure, organic synthesis will continue to advance as 
new methods and tools are added at its disposal and new challenges appear on its horizon. These challenges and opportunites will require increasingly colloborative and interdisciplinary research for their solution and full exploitation. The question of quo vadis synthesis? will always be asked, however, from time to time. It behooves its practitioners to look around them, think deeply about synthesis, and answer the question with their actions, which, hopefully, will always include its advancement for its own sake.

Despite current pressures from funding agencies, this author believes strongly in the importance of fundamental research and urges reassessment of the current trends, convinced of the deleterious effects on science that surely will be felt in the future. ${ }^{[49]}$

Acknowledgements: I am grateful to Alan J. Rocke, Robert F. Curl, $J r$., and John Buckingham for critically reading the manuscript and making astute and useful suggestions. I am also thankful to my students Christopher R. H. Hale, Philipp Heretsch and Christian Nilewski, as well as Janise Petrey for their help in preparing and editing this article.

Received: ((will be filled in by the editorial staff))

Published online on ((will be filled in by the editorial staff))

[1] G. Sarton, Ancient Science Through the Golden Age of Greece, Dover Publications, New York, 1980, p. 646.

[2] J. P. Mahaffy, What Have the Greeks Done for Modern Civilisation, G. P. Putnam's Sons, New York, 1910, p. 263.

[3] M. Berthelot, Collection de Anciens Alchimistes Grecs, Vol. 4 (Ed. Ch.Em Ruelle), G. Steinheil Publisher, Paris, 1888, p. 458.

[4] J. Buckingham, Chasing the Molecule, Sutton Publishing, Stroud, 2004, p. 259.

[5] R. E. W. Madison, The Life of the Honourable Robert Boyle, Taylor \& Francis, London, 1969, p. 332.

[6] A. J. Rocke, Chemical Atomism in the Nineteenth Century, From Dalton to Cannizzaro, Ohio State University Press, Columbus, 1984, p. 386 .

[7] A. J. Rocke, Image and Reality: Kekule, Kopp, and the Scientific Imagination, The University of Chicago Press, Chicago, 2010, p. 375.

[8] T. H. Levere, Transforming Matter: A History of Chemistry from Alchemy to the Buckyball, The Johns Hopkins University Press, Baltimore, 2001, p. 232.

[9] F. L. Holmes, Lavoisier and the Chemistry of Life, University of Madison Press, Madison, 1985, p. 565; J. P. Poirier, Lavoisier: Chemist, Biologist, Economist, University of Pennsylvania Press, Philadelphia, 1996, p. 516; M. S. Bell, Lavoisier in the Year of One: The Birth of a New Science in the Age of Revolution, W. W. Norton \& Company, New York, 2005, p. 214; D. I. Duveen, Sci. Am. 1956, 194, 84-95.

[10] K. C. Nicolaou, T. Montangon, Molecules That Changed the World, Wiley-VCH Publishers, Weinheim, 2008, p. 366.

[11] K. C. Nicolaou, E. J. Sorensen, Classics in Total Synthesis, VCH Publishers, Weinheim, 1996, p. 798; K. C. Nicolaou, S. A. Snyder, Classics in Total Synthesis II, Wiley-VCH Publishers, Weinheim, 1996, p. 636; K. C. Nicolaou, J. S. Chen, Classics in Total Synthesis III, Wiley-VCH Publishers, Weinheim, 2011, p. 743.

[12] a) E. J. Corey, X.-M. Cheng, The Logic of Chemical Synthesis, John Wiley \& Sons, New York, 1989, p. 436; b) E. J. Corey, B. Czakó and L. Kürti, Molecules and Medicine, Wiley Publishers, Weinheim,
2008, p. 254; c) E. J. Corey and L. Kürti, Enantioselective Chemical Synthesis, Direct Publishing Group, LLC, 2010, p. 336.

[13] E. C. Patterson, John Dalton and the Atomic Theory, Doubleday, Garden City, New York, 1970, p. 348.

[14] R. Keen, The Life and Work of Friedrich Wöhler, Teubner Verlag, Leipzig, Germany 1984.

[15] W. H. Brock, Justus von Liebig: the Chemical Gatekeeper, Cambridge University Press, Cambridge, 1997, p. 374

[16] J. B. Dumas, J. Pharm. 1834, 20, 261-294; On Dumas' substitution theory, see: S. C. Kapoor, Ambix 1969, 16, 1-65; N. W. Fischer, Ambix 1973, 20, 106-31, 209-233.

[17] M. Tiffenau, Correspondence de Charles Gerhardt, Vol. 1, Masson et Cie, Paris, 1918.

[18] W. G. Palmer, A History of the Concept of Valency to 1930, Cambridge University Press, Cambridge, 1965, p. 177.

[19] A. Kekulé, Ann. Chem.Pharm. 1858, 106, 129-159.

[20] A. S. Couper, Comptes rendus 1858, 1157-1160; A. Anschütz, Proc. R. Soc. Edinburgh, 1909, 29, 193-273.

[21] J. Loschmidt, Chemische Studien, Druck von Carl Gerald's Sohn, Vienna, 1861.

[22] S. Cannizzaro, Il nuovo cimento, 1858, 7, 321-366.

[23] A. Kekulé, Bull. Soc. Chim. 1865, 3, 98-110.

[24] T. Hager, Force of Nature, Simon \& Shuster, New York, 1995, p. 721.

[25] G. R. Desiraju, Nature 2000, 408, p.407.

[26] L. Pauling, The Nature of the Chemical Bond, Cornell University Press, New York, 1939, p. 664.

[27] a) W. J. Hehre, L. Radom, P. V. Schleyer, J. Pople, AB INITIO Molecular Orbital Theory, Wiley-Interscience, New York, 1986, p. 576; b) R. P. Par, W. Yang, Density-Functional Theory of Atoms and Molecules, Oxford University Press, New York, 1994, p. 352; c) W. Kohn, Rev. Mod. Phys. 1999, 71, 1253-1266; d) J. A. Pople, Rev. Mod. Phys. 1999, 71, 1267-1274; e) P. W. Atkins, R. Freidman, Molecular Quantum Mechanics, Oxford University Press, Oxford, 1999, p. 545

[28] F. Wöhler, Ann. Phys. Chem. 1828, 12, 253.

[29] C. A. Russell, Ambix, 1987, 34, 169-184.

[30] M. Berthelot, Chimie Organique, fondée sur la synthèse, MalletBacheher, Paris, 1860, pp. xv-xvi.

[31] H. Kolbe, Ann. Chem. Pharm. 1845, 54, 145.

[32] Nobel Laureates in Chemistry 1901-1992, Ed.: L. K. James, American Chemical Society and The Chemical Heritage Foundation, United States of America, 1993, p. 798.

[33] K. C. Nicolaou, S. A. Snyder, Angew. Chem. 2005, 117, 1036-1069; Angew. Chem. Int. Ed. 2005, 44, 1012-1044.

[34] L. Slater, Ambix 2001, 48, 161-189.

[35] H. T. Openshaw, R. Robinson, Nature 1946, 157, 438.

[36] R. B. Woodward, W. J. Brehm, A. L. Nelson, J. Am. Chem. Soc. 1947, 69, 2250.

[37] a) R. B. Woodward, M. P. Cava, W. D. Ollis, A. Hunger, H. U. Dainiker, K. Schenker, J. Am. Chem. Soc. 1954, 76, 4749-4751; b) R. B. Woodward, M. P. Cava, W. D. Ollis, A. Hunger, H. U. Dainiker, K. Schenker, Tetrahedron 1963, 19, 247-288.

[38] J. S. Cannon, L. E. Overman, Angew. Chem. 2012, 124, 4362-4386; Angew. Chem. Int. Ed. 2012, 51, 4288-4311. 
[39] O. T. Benfey, P. J. T. Morris, Robert Burns Woodward, Chemical Heritage Foundation, Philadelphia, 2001, p. 470.

[40] L. Slater, Stud. Hist. Phil. Sci. 2002, 33, 1-33.

[41] K. C. Nicolaou, D. Vourloumis, N. Winssinger, P. S. Baran, Angew. Chem. 2000, 112, 46-126; Angew. Chem. Int. Ed. 2000, 39, 44-122.

[42] For an early example of this chemical philosophy, see: a) E. J. Corey, K. C. Nicolaou, Y. Machida, C. L. Malmsten, B. Samuelsson, Proc. Natl. Acad. Sci. U.S.A. 1975, 72, 3355-3358; For recent examples from this laboratory, see: b) K. C. Nicolaou, S. Sanchini, D. Sarlah, G. Lu, T. R. Wu, D. K. Nomura, B. F. Cravatt, B. Cubitt, J. C. de la Torre, A. J. Hessell, D. R. Burton, Proc. Natl. Acad. Sci. U.S.A. 2011, 108, 6715-6720; c) K. C. Nicolaou, M. Lu, S. Totokotsopoulos, P. Heretsch, D. Giguère, Y. Sun, D. Sarlah, T. H. Nguyen, I. C. Wolf, D. F. Smee, C. W. Day, S. Bopp, E. A. Winzeler, J. Am. Chem. Soc., in press.

[43] J. D. Watson, The Double Helix, Touchstone, New York, 1968, p. 256.
[44] A. Eschenmoser, Angew. Chem. 2011, 123, 12618-12681; Angew. Chem. Int. Ed. Engl. 2011, 50, 12412-12472.

[45] T. E. Nielsen, S. L. Schreiber, Angew. Chem. 2008, 120, 52-61; Angew. Chem. Int. Ed. 2008, 47, 48-56.

[46] P. A. Wender, V. A. Verma, T. J. Paxton, T. H. Pillow, Acc. Chem. Res. 2008, 41, 40-49.

[47] K. C. Nicolaou, J. Med. Chem. 2005, 48, 5613-5638.

[48] H. Waldmann, Angew. Chem. 2012, 124, 6388-6389; Angew. Chem. Int. Ed. 2012, 51, 6284-6285.

[49] For further reading on the subject of this essay, see: In Atoms in Chemistry: From Dalton's Predecessors to Complex Atoms and Beyond (Ed.: C. Giunta), ACS Sympoisums Series Vol. 1044, American Chemical Society, Washington, DC, 2010 (In particular, see: D. E. Lewis, 150 Years of Organic Structures, Ch. 5).

[*] Prof. Dr. K. C. Nicolaou

Department of Chemistry and The Skaggs Institute for Chemical Biology, The Scripps Research Institute 10550 North Torrey Pines Road, La Jolla, CA 92037 (USA) and

Department of Chemistry and Biochemistry University of California, San Diego 9500 Gilman Drive, La Jolla, CA 92093 (USA) Fax: (+1) (858) 784-2469

E-mail: kcn@scripps.edu 


\section{Entry for the Table of Contents}

Layout 2:

\section{Total Synthesis}

K. C. Nicolaou*

Page - Page

The Emergence of the Structure of the Molecule and the Art of Its Synthesis

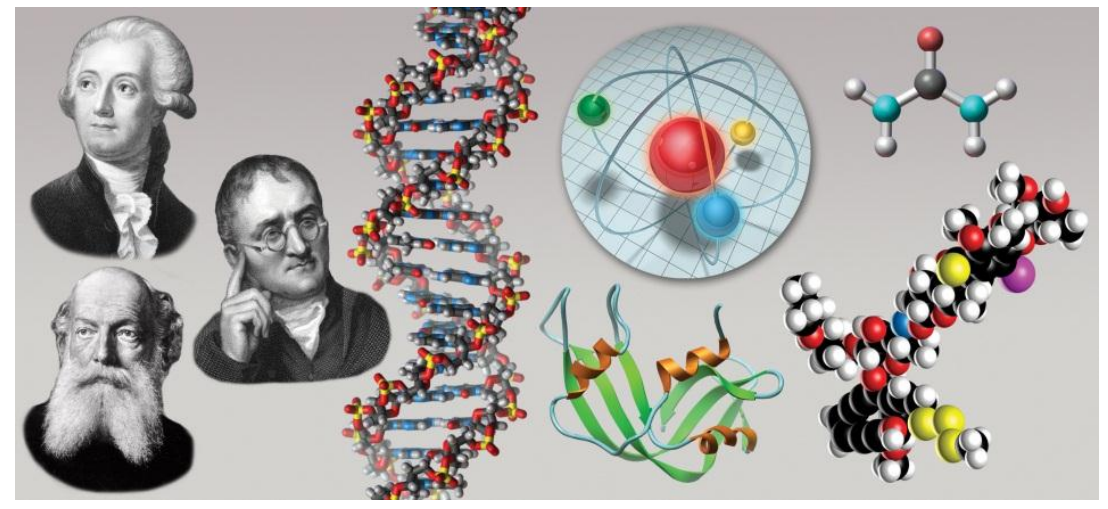

The birth of the science of the structure of the molecule and the art of its construction with emphasis on organic synthesis is traced from the end of the eighteenth century to the present day. 